\title{
UM TEATRO CONTEMPORÂNEO COMO LABORATÓRIO DA FANTASIA SOCIAL: ALGUNS APONTAMENTOS ACERCA DO TEATRO CHAMADO PÓS-DRAMÁTICO
}

Stephan Arnulf Baumgärtel ${ }^{1}$

O que é o teatro pós-dramático? Para Hans-Thies Lehmann (que não cunhou o termo, mas deu ampla visibilidade a ele com o seu livro de igual nome), o termo descreve um conjunto de práticas e estéticas teatrais bem diferentes entre si. No entanto, elas compartilham o impulso de enfraquecer a tríade ação, caráter e imitação ilusionista que formam a base do drama enquanto gênero teatral histórico. $\mathrm{Na}$ esteira deste enfraquecimento, o foco no uso do signo teatral se desloca do aspecto referencial para o aspecto expressivo². Súlvia Fernandes, no seu resumo crítico do livro de Lehmann enfatiza esta mudança na semiótica teatral:

Para Lehmann, o teatro pós-dramático não é apenas um novo tipo de escritura cênica. É um modo novo de utilização dos significantes no teatro, que exige mais presença que representação, mais experiência partilhada que transmitida, mais processo que resultado, mais manifestação que significação, mais impulso de energia que informação (FERNANDES, 2006: 9).

Nesta mudança consiste a proximidade com práticas performáticas, da qual fala Patrick Primavesi:

Deve-se compreender o conceito "teatro pós-dramático", segundo o estudo fundamental de Hans-Thies Lehmann, não de uma forma dogmática, como se fosse uma renúncia final do texto dramático. Antes,
'Professor da Universidade do Estado de Santa Catarina

${ }^{2}$ Para uma discussão crítica da suposta ruptura histórica entre teatro dramático e pós-dramático, que usa a "poética do espetáculo" como categoria analítica, ver Luiz Fernando Ramos (2006). Ramos frisa corretamente que 0 "cena-centrismo" no teatro pós-dramático encontra precedentes, entre outros, já no teatro elisabetano e no barroco espanhol. Mas é necessário enfatizar que no teatro chamado pósdramático, o enfoque no teatro como acontecimento performático não implica numa cena hipnótica ou panóptica, como no caso do teatro dramático.

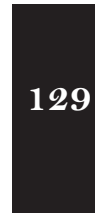




\section{Urdimento}

${ }^{3}$ Todas as traduções do alemão são de minha autoria.

\section{${ }^{4}$ Para uma analise} mais detalhada da transformação da cena teatral, durante 0 fim do séc. XIX, em direção a uma cena estruturalmente dividida entre um nível realista e um nível alegórico, ver especialmente Fuchs (1996).

${ }^{5}$ Neste contexto, é interessante comparar o relato crítico que Marco de Marinis (1987) esboça do movimento do happening com as características do teatro pós-dramático em Lehmann. Permite entender não só algumas características formais do teatro pós-dramático, herdadas do happening, mas também 0 seu projeto comum de construir uma zona híbrida em que o estético e o pragmático se entrelaçam e indagam.

${ }^{6}$ Brecht pensava num contexto depois da revolução socialista em que a própria sociedade, na sua organização social, já tivesse superado a distinção categórica entre jogo estético e prática pragmática (ver Guinsburg/

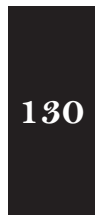

serve como uma ferramenta de trabalho para descrever várias formas novas de fazer teatro, com certa proximidade à performance, que seguem outros princípios do que aqueles das encenações tradicionais de uma obra dramática. Não se trata simplesmente de um estilo único, mas de um processo transformador mais longo, que conseguia liberar os parâmetros elementares do teatro (espaço, luz, corpo, movimento, gesto, voz, etc.) da sua submissão à obra dramática. Se as formas teatrais pósdramáticas criam espaços experimentais para percepções não-habituais, o fazem, sobretudo, porque possibilitam uma nova consciência da situação que o teatro significava, desde já, enquanto prática cultural: $o$ acontecimento de um encontro entre pessoas que apresentam algo $e$ pessoas que assistem a apresentação (PRIMAVESI, in: ARNOLD, 2004: 9$)^{3}$

Do ponto de vista formal, são os experimentos teatrais da vanguarda do séc. XX, principalmente aqueles do simbolismo e das concepções pictóricas da cena teatral em Appia e Craig, que prefiguram a formação do teatro pósdramático. Ambas formulam um teatro em que o universo humano e a figura humana em cena não formam mais o signo hegemônico, como no caso do drama burguês ${ }^{4}$. Depois da interrupção das experimentações por causa da ascensão de regimes totalitários nos anos 30 do século passado, é o movimento do happening que fornece, a partir dos anos 50, importantes impulsos para a formação de um teatro que interroga os limites entre o campo estético e o campo pragmático ${ }^{5}$. Podemos encontrar este interesse também nos experimentos formais de Bertolt Brecht nas suas peças didáticas. O teatro didático de Brecht se torna frutífero para o teatro pós-dramático na fronteira entre vida e arte, estabelecida pelo happening, e não dentro do contexto político visado por ele mesmo ${ }^{6}$.

Parece-me importante notar que em ambos os momentos históricos mencionados, a construção da cena enfraquece o sujeito visto como origem das ações; um sujeito autônomo, o que significa no contexto teatral também o enfraquecimento do ator como sujeito radicalmente oposto ao espectador. Os predecessores do teatro pós-dramático pretendem redefinir a relação entre vida e arte, entre o sujeito humano e a linguagem humana enquanto campo discursivo, no sentido de enfatizar os campos (sociais, discursivos, energéticos) nos quais o indivíduo burguês encontra-se inserido. Nestes movimentos vanguardistas encontramos a transformação do evento teatral de um evento representativo em um evento com características primordialmente expressivas e pragmáticas. Em termos espaciais, podemos constatar uma crescente integração entre espaço estético (palco) e espaço pragmático (platéia), para compor um único espaço híbrido. Para esta cena integrada me parece que haja dois perigos.

Um teatro contemporâneo como laboratório da fantasia social... Stephan Baumgärtel. Abril 2008 - № 9 
Primeiro, um perigo romântico, isto é, fechar a expressão no mundo estético, fetichizar a expressividade peculiar do signo estético, e desta forma, propor a utopia estética de que a vida pragmática deve e pode ser transformada numa existência estética ${ }^{7}$. Neste contexto a arte possui a força de um ideal que permite avaliar criticamente a realidade da vida social e pragmática como estrutura deficiente.

Segundo, há o perigo da banalização do campo estético, presente no happening e proveniente da não-hierarquia entre os signos e da inclusão do acaso como procedimento formador do seu processo criativo. Desta forma, a proposta do happening pode formular uma crítica ao mercado de arte e subverter o status idolatrado da arte enquanto obra, desprezar o fazer artístico enquanto produto e valorizá-lo enquanto processo e saber num contex to social específico. Aqui, o impulso é de transformar a arte em vida, em vez de fingir que seja a vida (idealizada).

Ambas as estratégias fazem parte da arte chamada pós-moderna. No entanto, para compreender os objetivos específicos do teatro pós-dramático, a mera análise formal da relação entre suas características e das de seus predecessores é insuficiente. É necessário avaliar e discutir como e com que finalidade este teatro usa a linguagem mais energética do que informativa, mais expressiva do que referencial, herdada das vanguardas do séc. XX. Uma analise das funções do legado vanguardista do séc. XX no teatro pós-dramático mostrará que este não pretende fechar a lacuna entre vida pragmática e existência estética, mas usá-la para problematizar a relação de ambos nas sociedades contemporâneas.

Segundo a citação de Primavesi, uma das intenções principais do teatro pós-dramático é inculcar percepções não-habituais nos seus participantes. Leio esta intenção como uma tentativa de recuperar o espaço teatral como um ambiente híbrido que permita manifestar um espírito de indagação, de inquietude, de incômodo, tanto perante o campo estético quanto o campo pragmático. É esta intenção que rege a busca por espaços e linguagens nãoconvencionais.

Desta forma, o teatro pós-dramático e a sua problematização cênica do personagem tradicional e do palco tradicional, pretendem formular uma resposta estética a uma situação política e cultural. O enfoque na situação teatral ganha uma importância muito além de uma inovação formal. HansThies Lehmann frisa que a ampla espetacularização da vida pública obriga um teatro que se compreende como crítico e investigativo a subverter as regras espetaculares que o regem:
${ }^{7}$ Uma utopia que encontra-se a partir do romantismo e que atravessa todo 0 pensamento estético do ocidente (ver Eagleton, 19...)

Abril 2008 - № 9 Um teatro contemporâneo como laboratório da fantasia social... Stephan Baumgärtel. 
Hoje em dia completa-se uma dinâmica que Guy Debord e os situacionistas previram como "a sociedade do espetáculo". Essa possui como uma característica determinante a definição dos cidadãos enquanto espectadores, para quais toda a vida pública se torna uma apresentação teatral. Neste sentido, somente aquele teatro se relaciona genuinamente com o político que abala o próprio regulamento, em vez de abalar qualquer outro: um teatro que interrompe o fazer teatral enquanto apresentação espetacular por construir situações em quais a inocência enganosa do 'espectar' é perturbada, infringida, tornada duvidosa. (2002:19)

Isso implica problematizar através da produção teatral de imagens o efeito anestésico que a imagem fabricada nas vias midiáticas produz. Por tanto, embutida na reconfiguração da comunicação palco-platéia (podemos dizer também, da questão de como integrar a experiência estética na vida pragmática) aparece como força formadora ao teatro pós-dramático a problemática da representação teatral, e a relação da representação teatral de imagens com outras formas de produzir imagens. Ambos se cruzam no arranjo do encontro, na estruturação da situação teatral. É por isso que o chamado teatro pósdramático foca criticamente a situação teatral, busca soluções formais para alertar o espectador à centralidade desse arranjo. O objetivo é fazê-lo refletir, a partir desse arranjo formal, sobre o status epistemológico do apresentado e sobre a sua cumplicidade com o apresentado, expresso no seu modo específico de participação. As semelhanças com a linguagem formal das vanguardas do séc. XX não devem nos enganar que "o arsenal de gestos expressivos no teatro pós-dramático serve para dar, sob as condições da onipresente tecnologia de informação, a resposta do teatro à nova comunicação social” (LEHMANN, 1999: 23).

Portanto, o teatro pós-dramático não é um teatro que simplesmente brinca com os elementos teatrais essenciais (corpo, movimento, voz, luz, espaço, etc.) enquanto elementos autônomos e de igual importância, como se fosse um grande playground (embora tal teatro pós-moderno existe). Mais do que isso, pretende discutir na sua estética não-mimética um problema sério e até existencial para uma sociedade democrática: como manter o pragmático e o estético, o senso do poder e o senso do possível, o hegemônico e o marginalizado ou até invisível, numa tensão produtiva, isto é, numa tensão que evite a homogeneização do espaço cênico, seja na direção do estético, seja na direção do pragmático. O espaço cênico integrado do teatro pós-dramático não é um espaço unificado. 
O dramaturgo Heiner Müller gostava de reiterar a formulação de Wolfgang Heise, um filósofo da antiga República Democrática Alemã, de que "o teatro é um laboratório da fantasia social". Enfatizamos que ele diz "fantasia social" e não simplesmente "fantasia”. Esta expressão, mais uma vez, relaciona de forma inquietante, portanto produtiva, o espaço estético e o espaço pragmático. Focaliza o papel indagador do teatro, e o caráter fundamentalmente provisório dos seus resultados. Segundo este conceito, o papel do teatro não é produzir mundos alternativos perfeitos com imagens idealizadas das possibilidades humanas, ou de entreter a sociedade com espetáculos de cunho revisteiro que se destacam através da sua combinatória hábil de signos engraçados. Mas a sua tarefa também não é de ilustrar o fim da civilização ocidental ou o fim da história. Antes, um "laboratório da fantasia social" pega material existente na sociedade humana e investiga como se pode imaginar uma transformação das estruturas sociais com este material. Os experimentos formais do teatro pósdramático (os enfoques na co-presença de atores e espectadores, na produção performativa de realidades e significados) encontram neste objetivo a sua razão. Este teatro contemporâneo usa uma linguagem pós-dramática, pois esta permite não só usar o material e a realidade social contemporânea para interrogá-la, mas principalmente encenar a própria interrogação.

Quem entra no laboratório da fantasia social, experimenta o social tanto como um espaço imaginado quanto vivenciado. $\mathrm{O}$ teatro enquanto laboratório social é um teatro que coloca em cena a sua busca por uma linguagem que possa manifestar o seu papel social crítico. A própria busca vira material cênico. Neste processo, apresenta ao espectador um espaço de sensações provisórias, de significados movediços, um sujeito pós-cartesiano que apercebe o mundo não através do filtro dos seus conceitos, mas recebe o mundo através de sensações que provocam o questionamento dos conceitos estabelecidos nos diferentes processos de aculturação e socialização. Nisso consistem percepções não-habituais, isto é, percepções que provocam criticamente os nossos hábitos, realçam o habitual para torná-lo duvidoso e discutível.

Os dois textos de pesquisadores do teatro pós-dramático alemão, traduzidos para este volume de Urdimento, um de Hans-Thies Lehmann e um de Erika Fischer-Lichte, falam de características desta pesquisa contemporânea. Ambos mostram que o teatro contemporâneo quer colocar os espectadores num estado "entre" diferentes campos de energia, ou na encruzilhada de forças vetoriais que o sujeito racional não pode controlar ou dominar: sejam elas as distintas forças do corpo e da libido ou de discursos sociais e políticos. O texto de Lehmann, escrito cinco anos antes da publicação de "O teatro pós-dramático" na Alemanha, sugere procedimentos de como

${ }^{8}$ Ver a entrevista com Bernard Umbrecht, in: Koudela (2003), p. 107 
aproximar-se a uma encenação pós-dramática. Propõe um modo de recepção que busca respostas não à pergunta “o que significa o espetáculo?”, mas à pergunta “o que quer fazer comigo?”A arte da não-compreensão é uma arte que permite que as sensações e percepções não-cognitivas possam intervir nos padrões de observação estabelecidos. Erika Fischer-Lichte, por sua vez, descreve alguns procedimentos de encenações pós-dramáticas que pretendem frustrar uma recepção primordialmente cognitiva. Para elucidar as implicações imaginativas desta proposta estética, ela evoca tanto os contextos políticos dos anos 90 quanto as pesquisas antropológicas acerca do interesse humano em estado liminares.

Iniciamos com estas traduções um projeto de publicar textos alemães sobre o teatro chamado pós-dramático. Esperamos que os trabalhos escolhidos ajudem a aguçar a sensibilidade do leitor acerca da noção do teatro pósdramático e mais ainda a instigar a sua curiosidade na prática real deste.

Referências

ARNOLD, Heinz Ludwig (org.) Theater fürs 21. Jahrhundert. München: Edition Text + Kritik, 2004.

FERNANDES, Silvia. Subversão no palco. In: Humanidades, (52) 2006. pp.718.

FUCHS, Elinor. The Death of Character. Perspectives on Theater after Modernism. Bloomington and Indianapolis: Indiana University Press, 1996.

GUINSBURG, Jacó e KOUDELA, Ingrid Dormien. Teatro da Utopia: Utopia do Teatro? In: KOUDELA, Ingrid Dormien (org.) Um Vôo Brechtiano. São Paulo: Perspectiva, 1992.

KOUDELA, Ingrid Dormien (org.) Heiner Müller. O Espanto no Teatro. São Paulo, Perspectiva, 2003

LEHMANN, Hans-Thies. Wie politisch ist postdramatisches Theater? in: Lehmann, Hans-Thies. Das Politische Schreiben. (Recherchen 12). Berlin: Theater der Zeit, 2002.

LEHMANN, Hans-Thies. Postdramatisches Theater. Frankfurt/Main: Verlag der Autoren, 1999.

MARINIS, Marco de. El nuevo teatro, 1947 - 1990. Buenos Aires e Barcelona: Ediciones Paidos, 1987.

PRIMAVESI, Patrick. Orte und Strategien postdramatischer Theaterformen. In: ARNOLD, Heinz Ludwig (org.) Theater fürs 21. Jahrhundert. München: Edition Text + Kritik, 2004, pp. 8-25.

RAMOS, Luiz Fernando. A pedra de toque. In: Humanidades, (52) 2006. pp.27-34.

WIRTH, Andrzej. Do Diálogo ao Discurso. In: O Tabuleiro, no.5..1984, pp. $8-14$

Um teatro contemporâneo como laboratório da fantasia social... Stephan Baumgärtel. Abril 2008 - № 9 